\title{
Interpretações Morfoestruturais da Drenagem da Bacia Hidrográfica do Rio do Peixe - Minas Gerais
}

\author{
Morphostructural Interpretations of the Drainage of the Peixe River Watershed- \\ Minas Gerais
}

\author{
Interpretaciones Morfoestructurales del Drenaje de la Cuenca Hidrográfica del Río \\ del Peixe - Minas Gerais
}

Isabela Belmira Santos Giarola ${ }^{1}$

\begin{abstract}
RESUMO: A morfometria é fundamental para o entendimento da dinâmica ambiental de uma determinada área. A análise morfométrica e morfológica em bacias hidrográficas visa 0 compreendimento do modelado do relevo e da dinâmica fluvial local e regional. Através da aplicação de parâmetros morfométricos pode-se avaliar quantitativamente o comportamento das bacias hidrográficas. A bacia hidrográfica do rio do Peixe, situada no sudeste do Estado de Minas Gerais, apresenta especificidades morfométricas quando comparada às áreas circunvizinhas. Com o intuito de investigar as características morfométricas da bacia supracitada, este trabalho tem como objetivo correlacionar dados obtidos a partir de perfis longitudinais e do índice de Relação Declividade $\mathrm{x}$ Extensão (RDE) para identificação de áreas anômalas das sub-bacias da bacia hidrográfica do rio do Peixe. Foram selecionados vinte canais fluviais de $5^{a}, 6^{a}, 7^{\underline{a}}$ e $8^{\mathrm{a}}$ ordem e, ao todo, foram encontradas 126 anomalias nesses canais, indicando que eles possuem padrão geomorfológico incomum. Essa configuração auxilia na explicação das diferenças altimétricas e leva a considerar a desnudação diferencial e a ação neotectônica como elementos essenciais na compreensão do relevo desta bacia.
\end{abstract}

PALAVRAS-CHAVE: Morfometria; Geomorfologia; Relação declividade x extensão.

ABSTRACT: The morphometric analysis is fundamental for understanding the environmental dynamics of any area, aiming the understanding the relief and the local and regional fluvial dynamics. It is possible to quantitatively evaluate the behavior of river basins. The Peixe River watershed, located in the southeastern of the state of Minas Gerais, has distinct morphometric data when compared to the surrounding areas. In order to investigate the morphometric characteristics of the Peixe River watershed, this study aims to correlate morphometric data obtained from longitudinal profiles and Stream-Gradient Index (SL index) to identify anomalous areas of the sub-basins of the Peixe River watershed. Twenty river channels of 5, 6, 7 and 8 order were selected. A total of 126 anomalies were found in these channels, indicating that they have a geomorphological unusual. This configuration assists in the explanation of the altimetric differences and leads to consider differential denudation and neotectonic action as essential elements in understanding the relief of this basin.

\footnotetext{
${ }^{1}$ Mestranda pelo Programa de Pós-Graduação em Geografia. Universidade Federal do Rio de Janeiro. isagiarola@hotmail.com.
} 
KEYWORDS: Morphometric; Geomorphology; SL index.

RESUMEN: La morfometría es fundamental para el entendimiento de la dinámica ambiental de una determinada área. El análisis morfométrico y morfológico en cuencas hidrográficas busca el entendimiento del modelado del relieve y de la dinámica fluvial local y regional. A través de la aplicación de parámetros morfométricos se puede evaluar cuantitativamente el comportamiento de las cuencas hidrográficas. La cuenca hidrográfica del río del Peixe, situada en el sureste del Estado de Minas Gerais, presenta en su cuenca especificidades morfométricas en comparación con las zonas circundantes. Con el fin de investigar las características morfométricas de la cuenca supra citada, este trabajo tiene como objetivo correlacionar datos obtenidos a partir de perfiles longitudinales y del índice de Relación Declividad x Extensión (RDE) para identificación de áreas anómalas de las subcuencas de la cuenca hidrográfica del río del Pescado. Se seleccionaron veinte canales fluviales de 5, 6, 7 y 8 orden, en total fueron encontradas 126 anomalías en esos canales, indicando que poseen patrón geomorfológico raro. Esta configuración ayuda en la explicación de las diferencias altimétricas y lleva a considerar la denudación diferencial y la acción neotectónica como elementos esenciales en la comprensión del relieve de esta cuenca.

PALABRAS-CLAVE: Morfometría; Geomorfología; Relación declive x extensión.

\section{INTRODUÇÃO}

As bacias hidrográficas são importantes para a investigação das características das variadas formas de relevo, pois elas auxiliam no entendimento da evolução do modelado terrestre. Muitos estudos sobre bacias hidrográficas tem um viés qualitativo, onde são interpretados os aspectos fisiográficos da área em questão. Entretanto, algumas especificidades ou generalidades podem passar despercebidas, fazendo com que seja necessário o emprego de técnicas quantitativas para complementar o estudo (ALVES; CASTRO, 2003). De acordo com Penteado (2011, p. 3) as bacias hidrográficas podem ser entendidas como uma: "[...] célula básica da análise ambiental permitindo reconhecer e avaliar seus diversos componentes e os processos de interação que nela ocorrem, devido à possibilidade do estudo dos elementos naturais e sociais que a compõem numa relação de causa e efeito".

Horton (1945) introduziu os estudos morfométricos na geomorfologia visando entender a configuração e a evolução das bacias hidrográficas (leis da composição de drenagem). A morfometria é feita com base nas principais medidas físicas de uma bacia hidrográfica, representando um avanço para a compreensão do modelado do relevo (CHEREM, 2008).

Para Barbosa e Furrier (2011, p. 11) "[...] os aspectos morfométricos das bacias hidrográficas refletem algumas das interrelações mais significativas entre os principais fatores responsáveis pela evolução e organização do modelado, em particular a geomorfologia". Os estudos relacionados com as drenagens fluviais sempre possuíram 
função relevante na geomorfologia, pois os cursos de água constituem os principais responsáveis no processo morfogenético mais ativos na esculturação da paisagem (ALCÂNTARA; AMORIM, 2005).

Parâmetros morfométricos auxiliam no entendimento da paisagem geomorfológica, pois ajudam a reconhecer os elementos geomórficos que identificam áreas sob a influência de atividades de natureza tectônica (PASSARELLA et al., 2016).

Outro meio de análise morfoestrutural da rede de drenagem, como importante elemento da evolução geomorfológica das paisagens de uma bacia hidrográfica, é através da relação entre a drenagem e a morfometria do relevo sobre o qual a mesma se insere. $A$ Relação Declividade x Extensão, ou simplesmente índice RDE, como denominada por Etchebehere (2000) foi inicialmente proposta por Hack (1973) e, segundo Etchebehere et al. (2006), é um indicador sensível de mudanças na declividade do canal fluvial "[...] que permite analisar a relação declividade e extensão do relevo e comparar com a estrutura de um canal fluvial" (BORGES; SILVA, 2017, p. 552).

Com a premissa de investigar as características morfométricas da bacia hidrográfica do rio do Peixe, objetivou-se correlacionar dados obtidos a partir de perfis longitudinais e do índice de Relação Declividade x Extensão (RDE) para identificação de áreas anômalas das sub-bacias de $5^{\underline{a}}, 6^{\underline{a}}, 7^{\mathrm{a}}$ e $8^{\underline{a}}$ ordem da bacia hidrográfica supracitada. A pesquisa procurou abordar os aspectos morfométricos dessas sub-bacias com o intuito de promover uma caracterização da área citada e contribuir para o entendimento de sua dinâmica hidrológica e geomorfológica.

\section{MATERIAL E MÉTODOS}

\section{Área de estudo}

A bacia hidrográfica do rio do Peixe está localizada no sudeste do Estado de Minas Gerais (Figura 1). A bacia é de $8^{\underline{a}}$ ordem de acordo com a hierarquia fluvial de Strahler (escala 1/50.000). Configura-se como uma bacia tributária da bacia do rio Paraibuna, um dos principais afluentes mineiros do rio Paraíba do Sul.

O principal curso d'água da bacia é o rio do Peixe, que possui uma extensão de 188 quilômetros e em seu trecho inicial recebe o nome de córrego da Serrinha, onde se encontram suas nascentes tradicionais, no município de Bom Jardim de Minas, em altitudes próximas a 1.200 metros. Sua foz ocorre na confluência com o rio Paraibuna, em uma altitude de 480 metros, no limite tríplice dos municípios de Matias Barbosa, Simão Pereira e Belmiro Braga. Sua bacia drena uma área de aproximadamente 2.373 quilômetros 
quadrados, nas mesorregiões da Zona da Mata Mineira e Sul/Sudeste de Minas (FELIPPE, 2014).

Figura 1 - Localização da Bacia Hidrográfica do Rio do Peixe

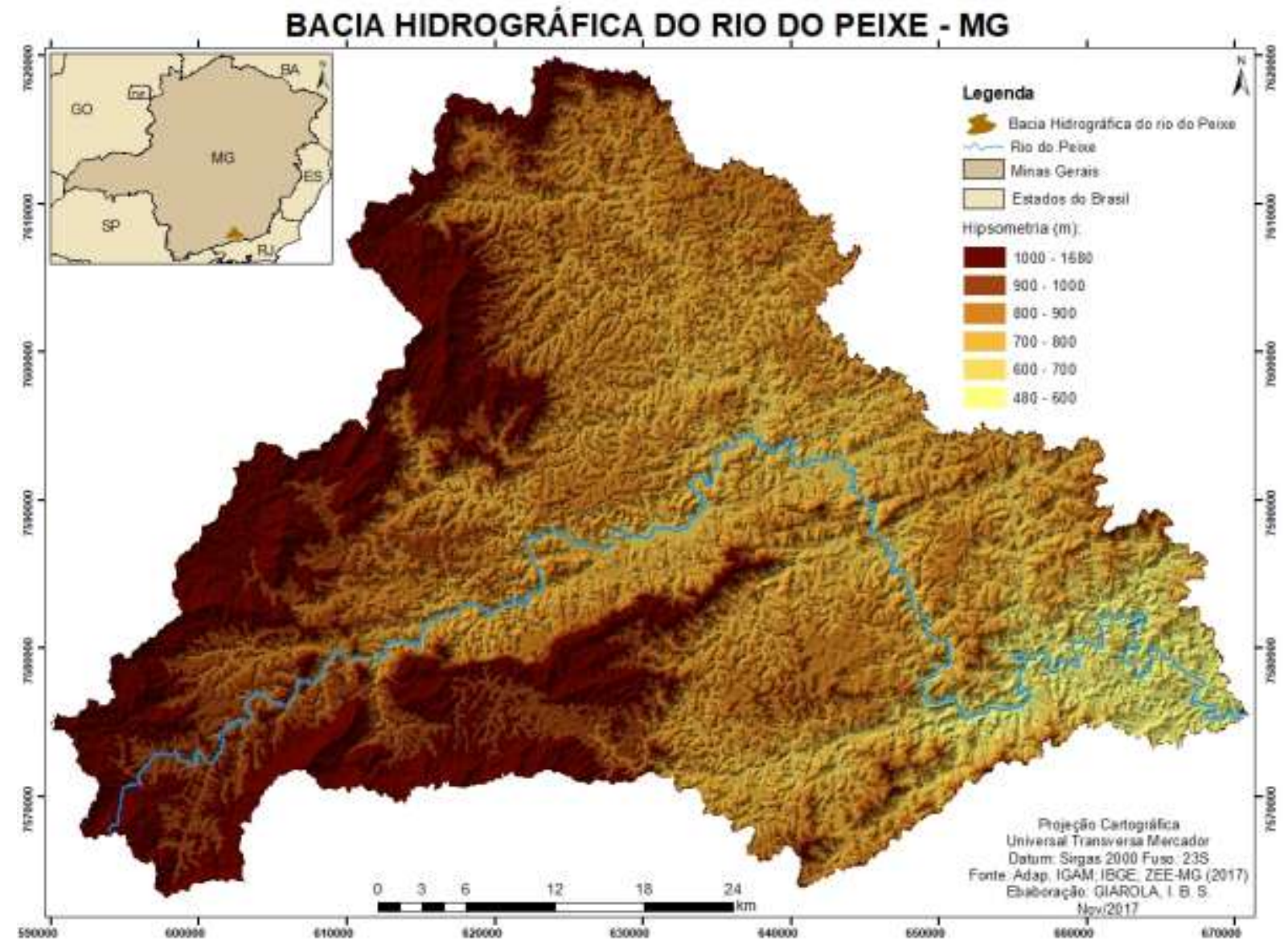

Fonte: Elaborado pela autora.

A bacia do rio do Peixe está inserida no domínio do clima tropical, sendo o clima da região, predominantemente, tropical úmido de altitude, brando, tipo Cwa segundo a classificação de Köppen, possuindo duas estações bem distintas: quente e chuvosa, nos meses de verão, e outra mais fria e seca, nos meses de inverno.

De acordo com o CPRM (2007), a região é embasada pelos litologias do Complexo Mantiqueira, da Suíte Pouso Alto, do Grupo Andrelândia, do Complexo Paraíba do Sul, do Complexo Juiz de Fora e o do Complexo Piedade. Está situada no que Ab'Saber (2007) denominou de Domínio Morfoclimático Tropical Atlântico, que é constituído por "Mares de Morros". Regionalmente, apresentam-se colinas e morros convexos a policonvexos com grande variabilidade de altura. O relevo dessa região se apresenta como movimentado, "amorreado" e serrano, com serras curtas e morros elevados de vertentes convexas (SCOLFORO; CARVALHO; OLIVEIRA, 2008). 
As características hipsométricas da bacia demonstram que as maiores altitudes são encontradas nos trechos de montante, constituídos de litologias mais resistentes, sobretudo em áreas serranas, embasadas pela unidade quartzítica do Grupo Andrelândia.

De acordo com o Projeto Radam-Brasil, morfologicamente, a bacia do rio do Peixe apresenta cinco compartimentos de relevo que, por sua vez, são subdivididos em unidades que apresentam feições específicas: a) Alinhamentos de Cristas do Vale do Rio Paraíba do Sul; b) Serranias da Zona da Mata Mineira; c) Planalto de Itatiaia; d) Planalto de Andrelândia; e) Planalto do Campo das Vertentes. (BRASIL, 1983).

\section{Aplicação do Índice Relação Declividade X Extensão - Índice RDE}

Para a aplicação do índice RDE na bacia do rio Peixe, elegeu-se os rios principais das sub-bacias de $5^{\underline{a}}, 6^{a}, 7^{\underline{a}}$ e $8^{\underline{a}}$ ordem. Foi gerada uma planilha no software Microsoft Excel 2013 com os valores das curvas de nível que cortam o canal fluvial da nascente até a foz. Posteriormente, através do cálculo manual da régua do software ArcGis 10.1, foi calculada a extensão de cada trecho do canal cortado por uma curva de nível.

O índice RDE foi obtido pela proposta de Etchebehere (2000), para a identificação de setores anômalos na rede de drenagem. Ainda segundo o autor e Fujita et al. (2011), as anomalias de $2^{2}$ ordem estão associadas às mudanças litológicas, lineamentos do relevo e confluência de rios, e as de $1^{\underline{a}}$ ordem às diferenças na resistência litológica, controle estrutural, e possível atividade tectônica. Para calcular o RDE trecho foi utilizada a seguinte equação:

$$
\operatorname{RDE}=(\Delta \mathrm{H} / \Delta \mathrm{L}) \cdot \mathrm{L}
$$

Onde: $\Delta \mathrm{H}=$ diferença altimétrica entre dois pontos extremos de um seguimento ao longo do curso d'água (20 metros); $\Delta \mathrm{L}=$ projeção horizontal da extensão do referido segmento; $L=$ comprimento total do curso d'água a montante do ponto para o qual o índice está sendo calculado.

Os resultados obtidos de cada trecho foram colocados em relação ao RDE total de cada curso d'água, pela equação:

$$
\text { RDEtotal }=\Delta \mathrm{H} / \log \mathrm{L}
$$

E posteriormente foi calculado o RDE trecho e RDE total, dividindo-se o resultado do RDE trecho pelo resultado do RDE total (Figura 2).

As anomalias foram classificadas a partir de parâmetro estabelecido por Seeber e Gornitz (1983), nas quais valores de RDE abaixo de dois indicam a inexistência de anomalias; entre duas e 10 anomalias de segunda ordem, e acima de 10 anomalias de primeira ordem, sendo posteriormente extraído o perfil longitudinal dos rios principais das bacias de $5^{\underline{a}}, 6^{\underline{a}}, 7^{\mathrm{a}}$ e $8^{\mathrm{a}}$ ordem no software Microsoft Excel 2013. 
Figura 2 - Esquema demonstrando o cálculo de RDE

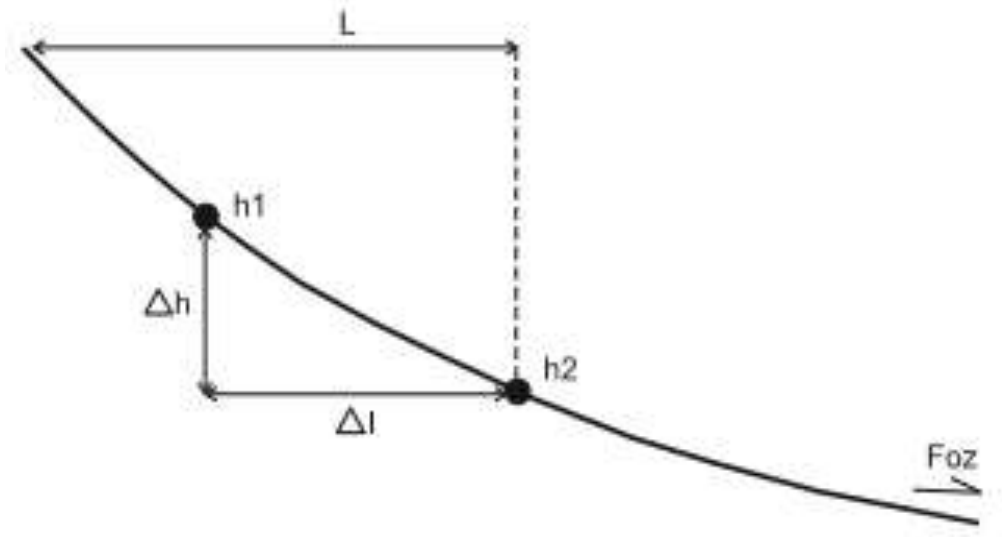

Fonte: Etchebehere (2000).

De acordo com Christofoletti (1981), o perfil longitudinal de um rio é dado a partir da relação entre as altitudes máxima e mínima com seu comprimento desde a nascente até a foz, podendo revelar sua declividade ao longo do canal fluvial. Sendo assim, os perfis longitudinais dos canais fluviais estudados foram obtidos pela medição da altitude e distância da foz (comprimento do canal) na intersecção das curvas de nível (intervalo de 20 metros) com a linha de drenagem, além disso, foram plotados os valores do RDE obtidos para cada canal.

\section{RESULTADOS E DISCUSSÃO}

Foram utilizados para aplicação do Índice Relação Declividade x Extensão 20 canais da bacia hidrográfica do rio do Peixe, tendo sido excluídos os de menor ordem, por não ser recomendada a aplicação deste índice em canais de pequena extensão (Figura 3).

$O$ rio do Peixe apresentou em sua extensão 13 anomalias, sendo 11 de $2^{a}$ ordem e duas de $1^{\text {a }}$ ordem (Figura 4A). Nas altitudes 1.080 metros e 1.060 metros, foram encontradas as primeiras anomalias do canal. São anomalias de $2^{\underline{a}}$ ordem, que estão sob o Grupo Andrelândia Unidade Quartzítica oriundo de metamorfismo regional, com litotipos de quartzito, xisto, biotitas, e gnaisses, dentre outros, que embasam as áreas com relevo de maior altitude. Nesse local, o rio se encaixa, indicando o controle estrutural.

Mais três anomalias (altitudes 960, 940 e 920 metros) de $2^{2}$ ordem foram encontradas, estão sobre terrenos do Complexo Mantiqueira. Após essa área de anomalias, o rio começa a ter a deposição como predominância. Porém, em um intervalo pequeno, ele novamente se encaixa, onde outra anomalia de $2^{\mathrm{a}}$ ordem é encontrada, caracterizando a mudança do Complexo Mantiqueira para o Grupo Andrelândia (altitude 780 metros). Nesses trechos, subitamente um rio meandrante se encaixa, indicando um controle estrutural. 
Figura 3 - Espacialização dos canais fluviais estudados

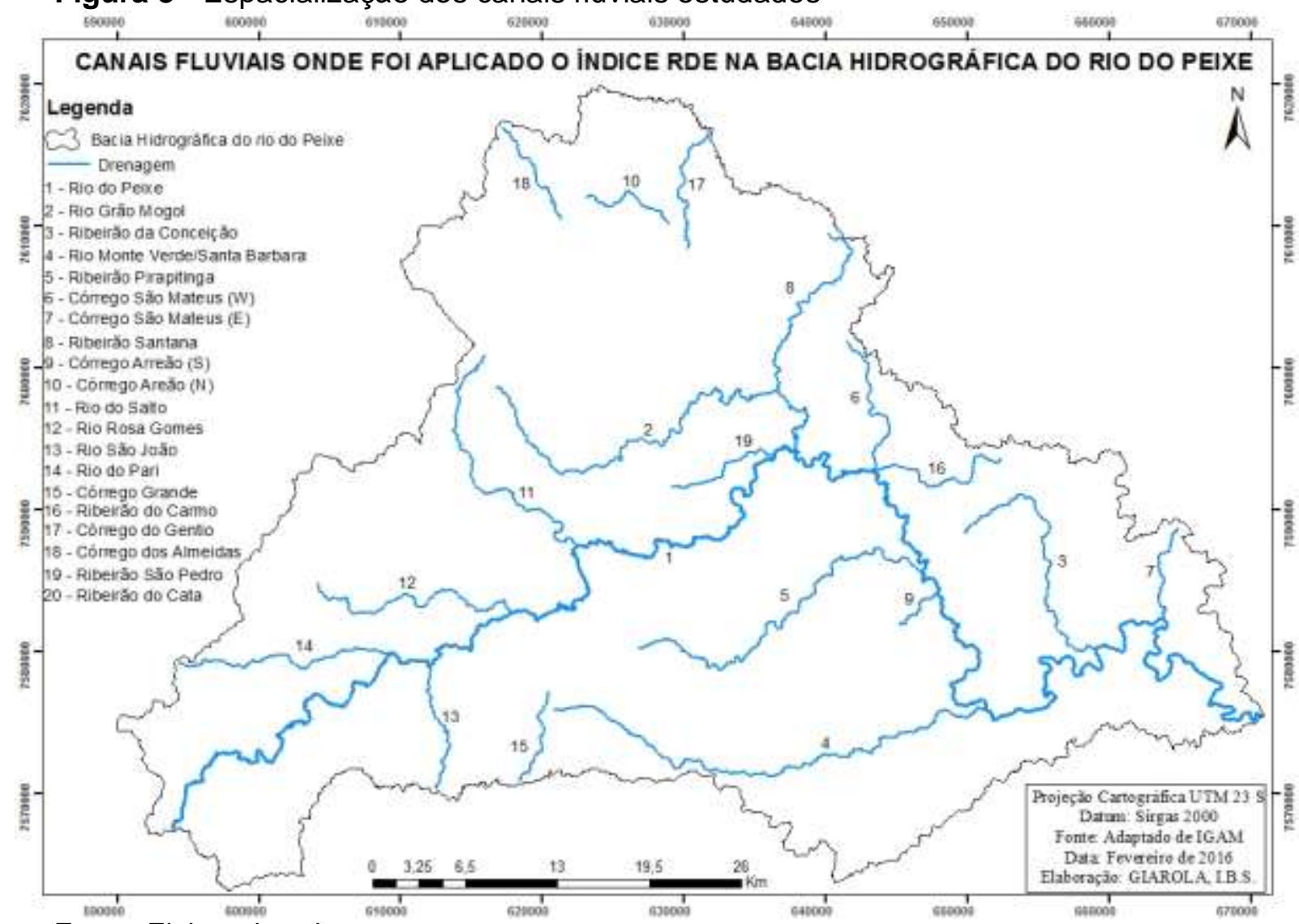

Fonte: Elaborado pela autora.

Aos 760 metros ocorre a primeira anomalia de $1^{\text {a }}$ ordem sob o Complexo Piedade, apresentando litologias paleoproterozóicas de biotita-hornblenda gnaisse e anfibolitos. Os limites deste complexo são marcados por zonas de falha (cisalhamento compressional), onde se encontram declividades expressivas (acima de $30 \%$ ), explicando o resultado.

Outra anomalia de $1^{\text {a }}$ ordem foi encontrada aos 560 metros, situada no Complexo Juiz de Fora - unidade tonalítica, composto por rochas ígneas e metamórficas, variantes de granitos e gnaisses. As outras quatro anomalias encontras a jusante são de $2^{\underline{a}}$ ordem, sob planícies altimontanas.

O rio do Peixe é o rio principal da bacia estudada. Assim, é normal que os ajustes morfológicos sejam de influência regional, podendo também ter influência pontual. Porém, pela sua extensão e área de drenagem, é mais comum que seja regional e, quando se observa as faixas de anomalias encontradas ao decorrer do rio, espera-se que os afluentes que cortam essas faixas tenham esse mesmo comportamento, como é o caso do rio Monte Verde/Santa Bárbara (Figura 4D). 
Figura 4 - Perfis longitudinais dos canais estudados: rio do Peixe (A), rio Grão Mogol (B), Ribeirão da Conceição (C), Monte Verde - Santa Bárbara (D)

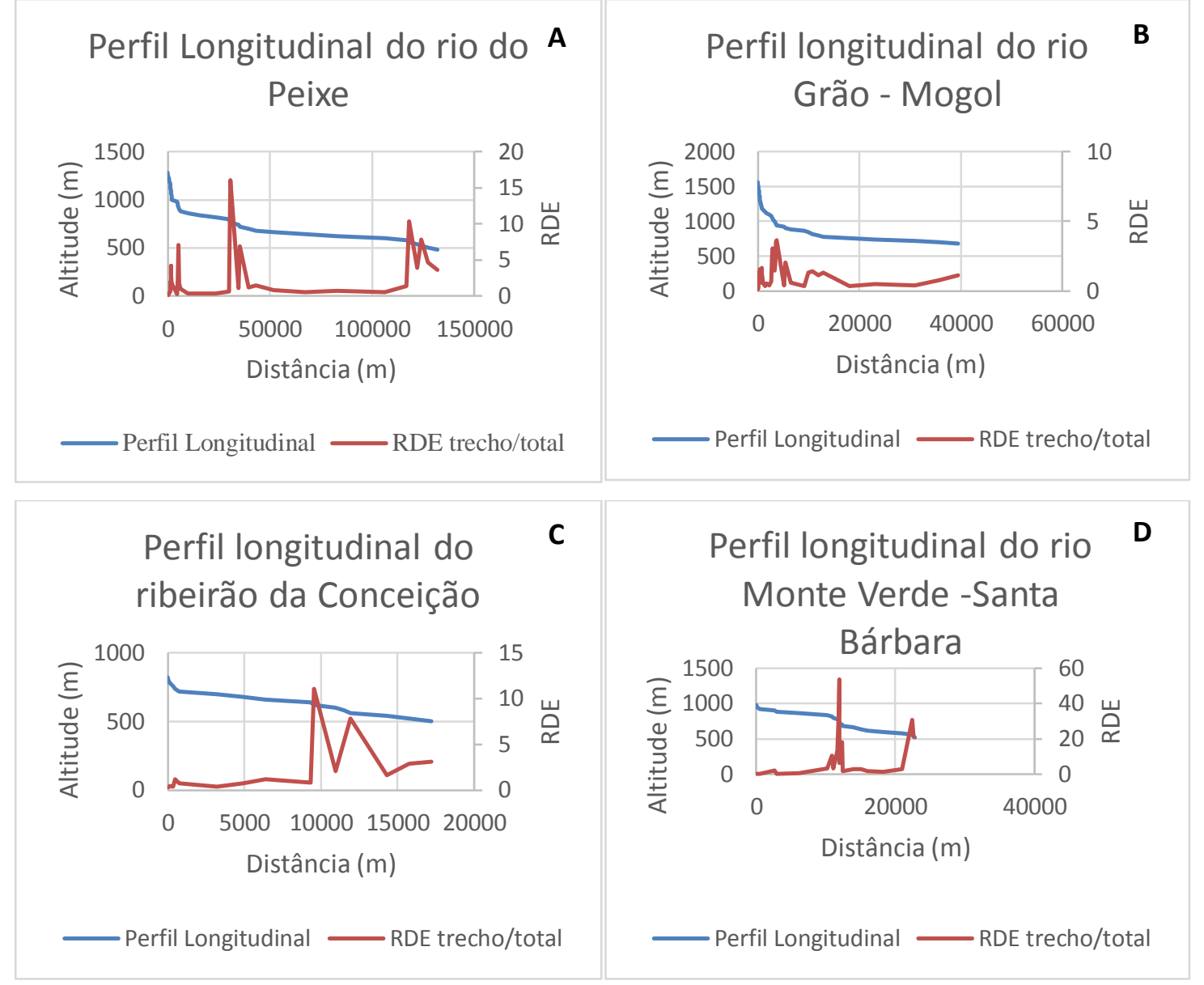

Fonte: Elaborado pela autora.

A anomalia de $2^{\text {a }}$ ordem encontrada na altitude de 500 metros está no contato com uma falha ou zona de cisalhamento transcorrente dextral, ilustrado no mapa geológico. Também pode ser observado nesse trecho a mudança do Complexo Juiz de Fora para o Grupo Andrelândia.

O rio Grão - Mogol (Figura 4B) apresentou três anomalias de $2^{\text {a }}$ ordem, estando concentradas no médio curso do rio, com altitudes de 960, 940 e 900 metros. As três anomalias estão inseridas no Grupo Andrelândia (unidade quartzítica). É um trecho onde o rio se encaixa, revelando um controle estrutural.

O ribeirão da Conceição (Figura 4C) apresentou cinco anomalias de $2^{\underline{a}}$ ordem e uma de $1^{\underline{a}}$ ordem. Localizado na porção leste da bacia hidrográfica do rio do Peixe, a anomalia de $1^{\underline{a}}$ ordem ocorre quando o rio sai de uma zona de planície e encaixa, estando sob o Complexo Juiz de Fora. Todas as anomalias estão concentradas em uma faixa, indicando controle litológico. Além disso, uma das anomalias (500 metros) está em uma área de falha ou zona de cisalhamento transcorrente dextral. 
Foram encontradas 14 anomalias para o rio Monte Verde/Santa Bárbara, onde se tem sete anomalias de $1^{\underline{a}}$ ordem e sete de $2^{\underline{a}}$ ordem. Quase todas as anomalias estão concentradas em uma faixa do rio.

Quando se observam as faixas de anomalias encontradas ao decorrer do rio principal (rio do Peixe), espera-se que os afluentes que cortam essas faixas tenham esse mesmo comportamento, e esse é o caso do rio Monte Verde/Santa Bárbara, onde os resultados encontrados no rio do Peixe se refletiram nele, ou seja, quando o rio Monte Verde/Santa Bárbara está preste a desaguar no rio principal da bacia pode-se constatar a incidência de várias anomalias. É muito provável que essas anomalias estejam associadas a falhas geológicas. Há várias planícies altimontanas, controle estrutural e ruptura de declive. Podese observar na Figura 4D a quantidade de "saltos" que o rio faz ao longo de seu percurso. A mudança litológica ao decorrer do rio é constante, passando por três unidades do Grupo Andrelândia e pelo Grupo Juiz de Fora.

Quatro anomalias de $2^{\underline{a}}$ ordem foram encontradas no ribeirão Pirapitinga. Essas anomalias são concentradas em um trecho (Figura 5A). Duas essas anomalias (720 e 700 metros) estão inseridas em falha ou zona de cisalhamento compressional, explicando tais anomalias. As outras duas anomalias (860 e 840 metros) situam-se na mudança de litologia, sendo do Grupo Andrelândia (unidade quartzítica) para o mesmo grupo, porém para a unidade Xistos e paragnaisses.

O córrego São Mateus (W) apesar de ser de pequena extensão (Figura 5B), apresentou duas anomalias, sendo uma de $1^{\underline{a}}$ ordem e outra de $2^{\underline{a}}$ ordem, sob o Complexo Piedade. As duas anomalias estão concentradas, indicando controle estrutural próximo a sua foz. Isso acontece, pois nesse trecho o córrego entra em uma área de controle estrutural.

No ribeirão Santana foram identificadas três anomalias de $2^{\text {a }}$ ordem (Figura $5 \mathrm{C}$ ). Essas anomalias estão inseridas no Complexo Piedade, encontradas em trecho de controle estrutural.

O córrego Areão $(\mathrm{N})$ apresentou uma anomalia de $2^{\mathrm{a}}$ ordem em sua extensão (Figura 5D), na altitude de $780 \mathrm{~m}$. Essa anomalia está associada a uma falha ou zona de cisalhamento compressional ali existente.

No rio do Salto foram observadas 24 anomalias, sendo nove de $1^{\text {a }}$ ordem (Figura 5E). Esta área estruturalmente é condicionada por zonas de falha com cisalhamento transcorrente compressional e, em pequena porção, por falhas transcorrentes dextrais, sendo encontradas duas anomalias de $1^{\underline{a}}$ ordem nesse local. O complexo Piedade encontrase próximo ao baixo curso do rio e apresenta litologias paleoproterozóicas de biotitahonblenda gnaisse e anfibolitos. 
Figura 5 - Perfis longitudinais dos canais estudados: ribeirão Pirapitinga (A), córrego São Mateus - W (B), ribeirão Santana (C), córrego Areão - N (D), rio do Salto $(E)$, rio São João $(F)$, rio Pari $(G)$, Córrego São Mateus - E $(H)$

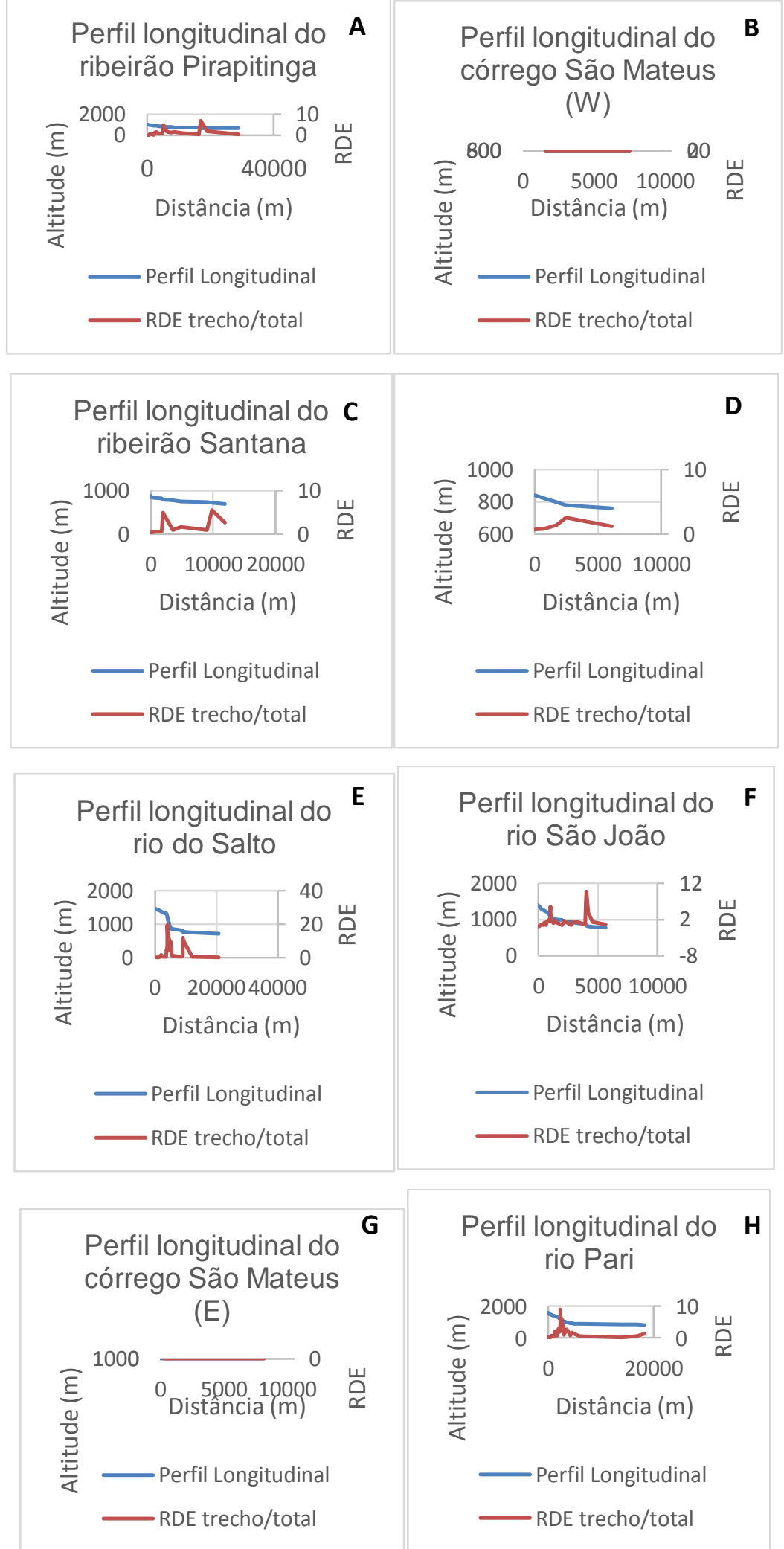

Fonte: Elaborado pela autora. 
Todas as outras anomalias estão concentradas no alto curso do canal fluvial, isso se deve ao fato da localidade do rio do Salto apresentar relevos condicionados por expressivos lineamentos estruturais e controle litológico diferencial. Soma-se a isso o fato da área estar localizada em um compartimento geomorfológico aclamado na literatura como tectonicamente ativo, além de ter um compartimento de maior energia, associado à Serra de Ibitipoca.

Os canais da bacia estão sob controle litológico, onde se situam importantes zonas de cisalhamento geomorfologicamente expressas pelas serras quartzíticas do Ibitipoca e Lima Duarte, bem como a Serra Negra.

É possível constatar cinco anomalias de $2^{\underline{a}}$ ordem no rio São João (Figura 5F). Três dessas anomalias são encontradas a jusante do rio (860, 840 e 820 metros), local onde há presença de falhas ou zonas de cisalhamento compressional e concomitantemente ocorre a mudança litológica do Complexo Piedade para o Grupo Andrelândia. Já as outras duas anomalias são vistas a montante do canal fluvial (1.100 e 1.080 metros), saindo de planícies e entrando em controle litológico.

Quinze anomalias de $2^{-a}$ ordem foram encontradas no rio Pari (Figura $5 \mathrm{G}$ ), todas elas estão sob o Complexo Mantiqueira e concentradas em um trecho do rio, indicando fortemente controle estrutural na área.

No córrego São Mateus (E) apresentou sete anomalias (Figura $5 \mathrm{H}$ ), sendo três de $1^{\text {a }}$ ordem. Essas três anomalias supracitadas concentram-se em linhas de falhas ou zonas de cisalhamento transcorrente dextral, explicando tais anomalias. Já as anomalias de $2^{\underline{a}}$ ordem ocorreram justamente na mudança do Complexo Juiz de Fora Unidade Charmoquítica para o mesmo Complexo, porém para a Unidade Tonalítica.

Foram identificadas cinco anomalias de $2^{2}$ ordem para o córrego Grande (Figura 6A), elas estão em um local onde há mudança litológica do Grupo Andrelândia Unidade Quartzítica para a Unidade Xisto e Paragnaissesa presença de falha ou zona de cisalhamento compressional. Além disso, estão compreendidas sob uma linha de falha ou zona de cisalhamento compressional.

Três anomalias de $2^{\underline{a}}$ ordem foram indicadas no ribeirão do Carmo (Figura 6B). Elas estão concentradas em um trecho do canal (700, 680 e 660 metros), onde é possível identificar a presença de falha ou zona de cisalhamento transcorrente dextral, sob o Grupo Andrelândia.

No córrego do Gentio (Figura 6C) localizado na porção norte da bacia hidrográfica do rio do Peixe, apenas uma anomalia de $2^{\underline{a}}$ ordem foi encontrada. Anomalia essa que está inserida sob um controle estrutural, pertencendo ao Complexo Piedade. 
Figura 6 - Perfis longitudinais dos canais estudados: córrego Grande (A), ribeirão do Carmo (B), Córrego do Gentio (C), córrego Areão - S (D), córrego dos Almeidas (E), ribeirão São Pedro $(F)$, ribeirão da Cata $(G)$, Rosa Gomes $(H)$

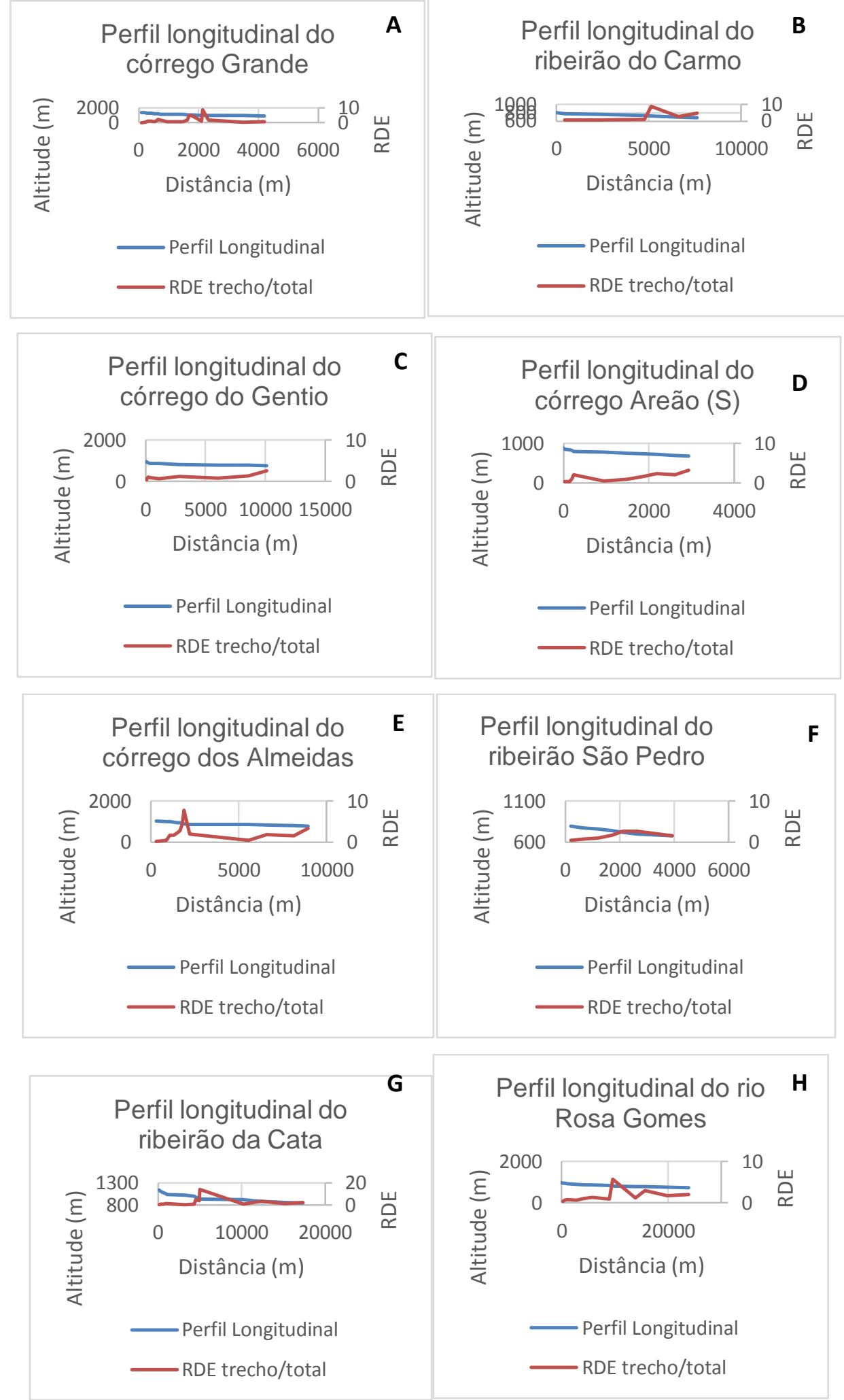

Fonte: Elaborado pela autora. 
Quatro anomalias de $2^{\underline{a}}$ ordem podem ser identificadas no córrego Areão (S). Essas anomalias estão na linha onde se encontra a mudança do Grupo Andrelândia para o Complexo Juiz de Fora (Figura 6D).

Foram encontradas 16 anomalias de $2^{\underline{a}}$ ordem no Córrego dos Almeidas (Figura 6E) estando todas concentradas em uma determinada área, embasada sob o Grupo Andrelândia. Nessa linha de anomalias há um controle estrutural.

Duas anomalias de $2^{\underline{a}}$ ordem estão presentes no ribeirão São Pedro (Figura 6F). Essas anomalias indicam rupturas de declive no local. Uma anomalia de $1 \underline{a}$ ordem e quatro de $2^{\mathrm{a}}$ ordem foram encontradas no ribeirão da Cata (Figura 6G) embasadas pelo Complexo Piedade. As anomalias estão concentradas, havendo um controle litológico forte na área.

Três anomalias de $2^{\underline{a}}$ ordem foram detectadas no rio Rosa Gomes (Figura 6H). Essas anomalias acontecem nas intermediações de mudança litológica, onde se passa do Complexo Piedade para o Grupo Andrelândia.

Ao todo foram identificadas 126 anomalias na bacia hidrográfica do rio do Peixe, sendo especializadas na Figura 7. A bacia hidrográfica estudada apresenta relevos condicionados por expressivos lineamentos estruturais e controle litológico diferencial. A ocorrência de formações quartzíticas em meio a granitoides (Quadro 1) promove significativa diferença de resistência ao trabalho fluvial, o que pode explicar a heterogeneidade dos resultados encontrados.

Os canais analisados possuem um padrão geomorfológico sensivelmente distinto das bacias hidrográficas circunvizinhas. Se por um lado apresentam relevos condicionados por expressivos lineamentos estruturais e controle litológico em sua porção sudoeste-nordeste, traz padrões fluviais meandrantes em extensas planícies aluviais intervaladas por rupturas de declive em sua baixa porção. Tais aspectos levam a morfologias fluviais distintas, comumente associadas a contextos de atividade neotectônica.

Além disso, um lineamento de cristas se estende na porção sul da bacia configurando os patamares de cimeira da Serra Negra e da Serra de Lima Duarte. A foz da bacia no rio Paraibuna possui altitude inferior a 600 metros, onde o rio principal se abre em vales amplos com planícies aluviais extensas. Sua porção norte possui relevo mais declivoso, com altitudes comumente superiores a 800 metros, recortadas por inúmeros pequenos vales fluviais encaixados de cursos retilíneos controlados, muitas vezes, estruturalmente. A porção central da bacia, nas margens do rio principal, apresenta uma sequência de planícies altimontanas, provavelmente associadas ao acúmulo de material gerado pela influência da Serra de Lima Duarte.

Desse modo, a bacia hidrográfica não apresenta padrão convencional, com a formação de degraus marcando a passagem desse nível de planícies para o nível imediatamente inferior (de foz). A guisa de síntese, a interpretação da espacialidade das 
anomalias permite segmentar a porção norte da bacia em um compartimento de maior energia, associado à Serra de Ibitipoca; um segundo compartimento corta a bacia no sentido SW-NE, marcando os terrenos predominantemente xistosos; um último setor refere-se a baixa porção da bacia que, não por coincidência, encontra-se embasada pelos granitoides paleoproterozóicos.

Figura 7 - Espacialização das anomalias encontradas.

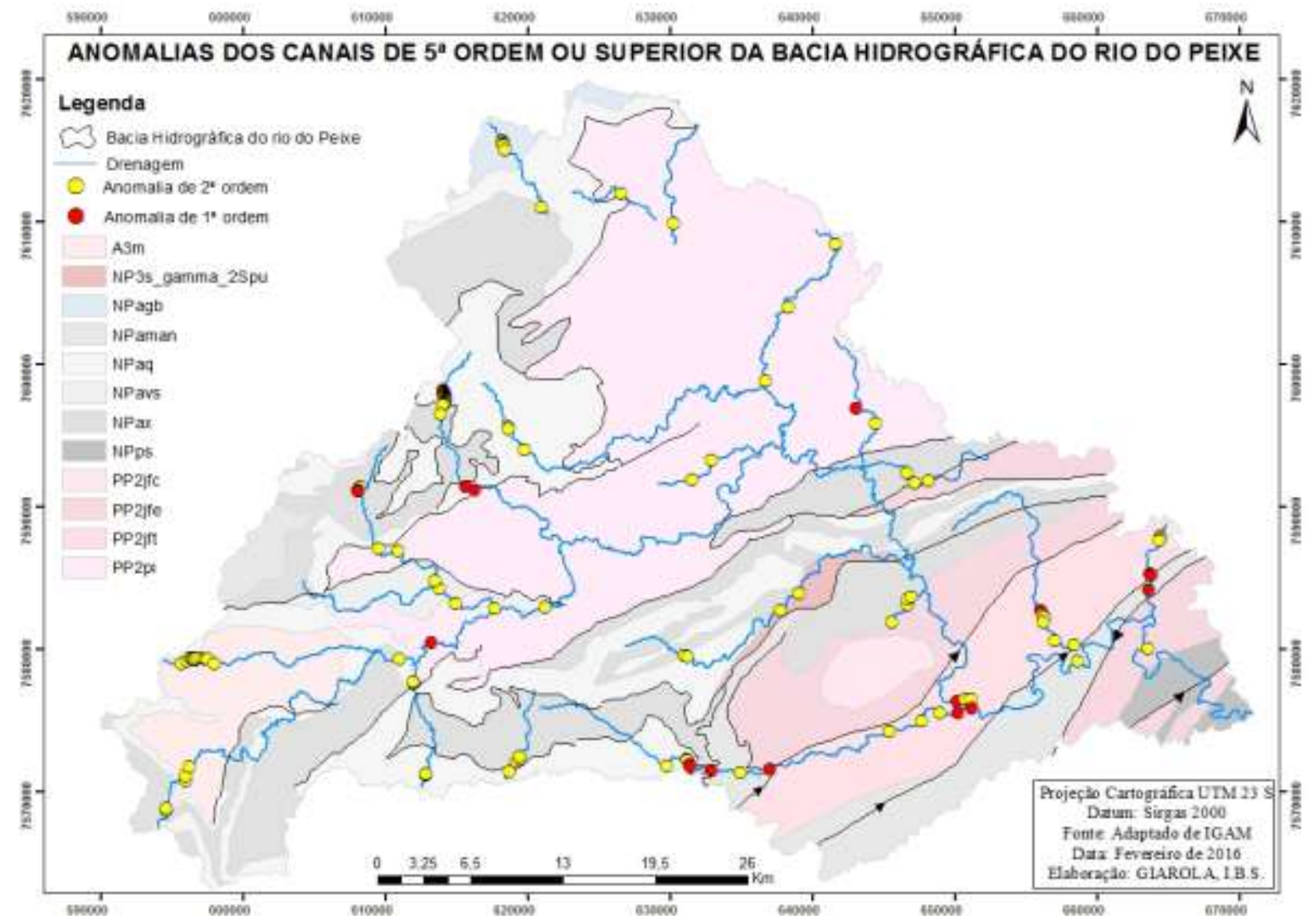

Fonte: Elaborado pela autora.

Quadro 1 - Litologia da bacia hidrográfica do rio do Peixe

\begin{tabular}{|c|l|}
\hline Sigla & \multicolumn{1}{|c|}{ Litologia } \\
\hline PP2pi & Complexo Piedade \\
\hline PP2jft & Complexo Juiz de Fora - unidade tonalítica \\
\hline PP2jfe & Complexo Juiz de Fora - unidade enderbítica \\
\hline PP2jfc & Complexo Juiz de Fora - unidade charnoquítica \\
\hline NPps & Complexo Paraíba do Sul \\
\hline NPax & Grupo Andrelândia - unidade Xistos e Paragnaisses \\
\hline NPavs & Grupo Andrelândia - unidade metavulcanossedimentar \\
\hline NPaq & Grupo Andrelândia - unidade quartzítica \\
\hline NPaman & $\begin{array}{l}\text { Grupo undrelândia unidade } \\
\text { migmatitosparaderivadosnebulíticos ou schilieren }\end{array}$ \\
\hline NPagb & $\begin{array}{l}\text { Grupo Andrelândia - unidade gnáissica com intercalações de } \\
\text { quartzitos, anfibolitos e metaultramáficas }\end{array}$ \\
\hline NP3s & Gamma_2Spu, Suíte, Suíte Pouso Alto \\
\hline A3m & Complexo Mantiqueira \\
\hline
\end{tabular}

Fonte: Elaborado pela autora. 
Essa configuração auxilia na explicação das diferenças altimétricas e leva à considerar a desnudação diferencial e a ação neotectônica como elementos essenciais na compreensão do relevo da bacia do rio do Peixe. Desta maneira, essas interpretações explicam o alto número de anomalias encontradas nos canais fluviais.

\section{CONCLUSÕES}

As singularidades constatadas ao norte e ao oeste da bacia hidrográfica do rio do Peixe podem ter relação com a variação litológica, pois as sub-bacias perpassam o Complexo Mantiqueira, o Grupo Andrelândia e também o Complexo Juiz de Fora. Além disso, se pode atribuir as variações encontradas às diferenças altimétricas, pois ao comparar o mapa de padrões e singularidades com o mapa hipsométrico foi constatado que as sub-bacias que apresentaram diferenciações entre si encontram-se em áreas com relevantes variações altimétricas.

As técnicas morfométricas que exploram atributos relacionados aos perfis ou ao traçado dos cursos d'água apresentam um potencial relativamente elevado para a detecção e a avaliação de deformações, sendo essenciais para análise de bacias hidrográficas.

As anomalias encontradas com a aplicação do Índice RDE estão sob falhas ou zonas de cisalhamento, controle estrutural na região ou mudança de litologia ou estrutura. Contudo, reitera-se que várias anomalias foram encontradas nas zonas de cisalhamento expressas pelas serras quartzíticas do Ibitipoca e Lima Duarte, bem como a Serra Negra.

\section{REFERÊNCIAS}

AB'SABER, A. N. Os domínios de natureza do Brasil: potencialidades paisagísticas. São Paulo: Editorial, 2007.

ALCÂNTARA, E. H.; AMORIM, A. de J. Análise morfométrica de uma bacia hidrográfica costeira: um estudo e caso. Caminhos da Geografia, Uberlândia, v. 14, n. 7, p. 70-77, fev. 2005.

ALVES, J. M. P.; CASTRO, P. T. A. Influência de feições geológicas na morfologia da bacia do rio Anque (MG) baseada no estudo de parâmetros morfométricos e análise de padrões de lineamentos. Revista Brasileira de Geociências, São Paulo, v. 33, n. 2, p. 117-127, jun. 2003.

BARBOSA, M.; FURRIER, M. Caracterização geomorfológica com apoio de índices morfométricos: o estudo de caso da bacia do rio Guruji. Cadernos do Logepa, João Pessoa, v. 6, n. 1, p. 1-24, jan./ jun. 2011.

BORGES, M. S.; SILVA, K. C. Análise do perfil longitudinal e aplicação de índice de Hack no córrego Rico no município de Paracatu - MG. In: SIMPÓSIO BRASILEIRO DE GEOGRAFIA 
FÍSICA APLICADA, 2017, Campinas, SP. E-book... Campinas: UNICAMP, 2017. p. 552 561.

BRASIL. Ministério das Minas e Energia. Departamento Nacional da Produção Mineral. Projeto RADAM-BRASIL. Folhas S.F. 23/24 Rio de Janeiro/Vitória: Rio de Janeiro: geologia, geomorfologia, pedologia, vegetação, uso potencial da terra. 1983. Rio de Janeiro, 1983. Levantamento de recursos naturais, 32.

CHEREM, L. F. S. Análise morfométrica da bacia do alto Rio das Velhas: comparação de metodologias e dados. 2008. Dissertação (Mestrado em Análise e Modelagem de Sistemas Ambientais) - Universidade Federal de Minas Gerais, Belo Horizonte.

CHRISTOFOLETTI, A. Geomorfologia fluvial: o canal fluvial. São Paulo: E. Blücher, 1981. CPRM. Serviço Geológico do Brasil. Mapa de domínios e subdomínios hidrogeológicos do Brasil. Rio de Janeiro, 2007.

ETCHEBEHERE, M. L. C. et al. Detecção de prováveis deformações neotectônicas no vale do Rio do Peixe, região ocidental paulista mediante aplicação de índices RDE (Relação Declividade-Extensão) em segmentos de drenagem. Geociências, São Paulo, v. 25, n. 3, p. 271-287, 2006.

ETCHEBEHERE, M. L. C. Terraços neoquaternários no Vale do Rio do Peixe, Planalto Ocidental Paulista: implicações estratigráficas e tectônicas. 2000. Tese (Doutorado em Geociências) - Universidade Estadual Paulista, Rio Claro.

FELIPPE, M. F. Morfometria da Bacia Hidrográfica do Rio do Peixe: identificação de padrões e singularidades. Juiz de Fora, MG: Universidade Federal de Juiz de Fora, 2014. Projeto de Iniciação Científica.

FUJITA, R. H. et al. Perfil longitudinal e a aplicação do índice de gradiente (RDE) no rio dos Patos, bacia hidrográfica do rio Ivaí, PR. Revista Brasileira de Geociências, São Paulo, v. 4, n. 41, p. 597- 603, dez. 2011.

HACK, J. T. Stream-profile analysis and stream gradient index. Journal of Research of the US Geological Survey, Reston, v. 1, n. 4, p. 421-429, 1973.

HORTON, R. E. Erosional development of streams and their drainage basins: Hydrographical approach to quantitative morphology. Geological Society of America Bulletin, New York, v. 56, n. 2, p. 275-370, 1945.

PASSARELLA, S. et al. Morfometria da bacia do Rio São João, MG: uma proposta de entendimento dos limites e da dinâmica das superfícies erosivas. Revista Brasileira de Geomorfologia, São Paulo, v. 17, n. 2, p. 241-252, abr./jun. 2016.

PENTEADO, A. F. Mapeamento e análise geomorfológicos como subsídios para identificação e caracterização de terras inundáveis. Estudo de caso da bacia hidrográfica do Rio dos Sinos-RS. 2011. Tese (Doutorado em Geografia Física) - Universidade de São Paulo, São Paulo.

SCOLFORO, J. R. S.; CARVALHO, L. M. T; OLIVEIRA, A. D. Zoneamento ecológicoeconômico do Estado de Minas Gerais: componentes geofísico e biótico. Lavras: UFLA, 2008.

SEEBER, L.; GORNITZ, V. River profiles along the Himalayan arc as indicators of active tectonics. Tectonophysics, International Journal of Geotectonics and the Geology and Physics of the Interior of the Earth, Amsterdam, v. 92, p. 335-367, 1983.

Recebido: julho de 2017. Aceito: junho de 2018. 